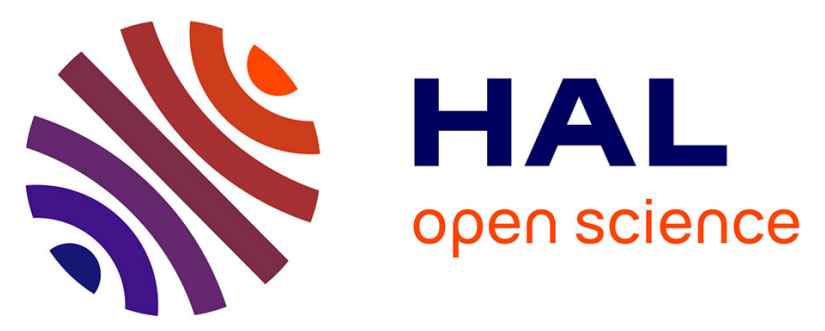

\title{
Efficacy and Safety of Tumor Necrosis Factor Antagonists in Treatment of Internal Fistulizing Crohn's Disease
}

\author{
Guillaume Bouguen, Audrey Huguet, Aurelien Amiot, Stéphanie Viennot, \\ Franck Cholet, Maria Nachury, Mathurin Flamant, Jean-Marie Reimund, \\ Véronique Desfourneaux, Arnaud Boureille, et al.
}

\section{To cite this version:}

Guillaume Bouguen, Audrey Huguet, Aurelien Amiot, Stéphanie Viennot, Franck Cholet, et al.. Efficacy and Safety of Tumor Necrosis Factor Antagonists in Treatment of Internal Fistulizing Crohn's Disease. Clinical Gastroenterology and Hepatology, 2020, 18 (3), pp.628-636. 10.1016/j.cgh.2019.05.027 . hal-02152872

\section{HAL Id: hal-02152872 \\ https://hal-univ-rennes1.archives-ouvertes.fr/hal-02152872}

Submitted on 1 Jul 2019

HAL is a multi-disciplinary open access archive for the deposit and dissemination of scientific research documents, whether they are published or not. The documents may come from teaching and research institutions in France or abroad, or from public or private research centers.
L'archive ouverte pluridisciplinaire HAL, est destinée au dépôt et à la diffusion de documents scientifiques de niveau recherche, publiés ou non, émanant des établissements d'enseignement et de recherche français ou étrangers, des laboratoires publics ou privés. 


\section{EFFICACY AND SAFETY OF TUMOR NECROSIS FACTOR ANTAGONISTS IN TREATMENT OF INTERNAL FISTULIZING CROHN'S DISEASE}

\section{Short title: anti-TNF and internal fistulizing disease}

Guillaume Bouguen ${ }^{1}$, Audrey Huguet ${ }^{2}$, Aurélien Amiot ${ }^{3}$, Stéphanie Viennot ${ }^{4}$, Franck Cholet ${ }^{5}$, Maria Nachury ${ }^{6}$, Mathurin Flamant ${ }^{7}$, Jean-Marie Reimund ${ }^{8}$, Véronique Desfourneaux ${ }^{2}$, Arnaud Boureille $^{9}$, Laurent Siproudhis ${ }^{1}$, on behalf of the GETAID group

${ }^{1}$ CHU Rennes, Univ Rennes, INSERM, CIC1414, Institut NUMECAN (Nutrition Metabolisms and Cancer), F-35000 Rennes, France

${ }^{2}$ CHU Rennes, Univ Rennes, F-35000 Rennes, France

${ }^{3}$ Department of Gastroenterology, Henri Mondor Hospital, APHP, EC2M3-EA 7375, Paris

Est-Créteil (UPEC) Val de Marne University, Creteil, France

${ }^{4}$ Hépato-Gastro-Entérologie et Nutrition, CHU de Caen, Caen, France

${ }^{5}$ CHRU Brest, Service d'Hépato-gastro-entérologie, Brest, France

${ }^{6}$ CHU Lille, University of Lille 2, Inserm Unit 995, F-59000 France

${ }^{7}$ Clinique Jules Verne and CHU de Nantes, Institut des Maladies de l'Appareil Digestif, Hotel Dieu, Nantes, France

${ }^{8}$ Hôpitaux Universitaires de Strasbourg (Hôpital de Hautepierre) et INSERM U1113 IRFAC (Interface de Recherche Fondamentale et Appliquée en Cancérologie), Université de Strasbourg, Strasbourg, France

${ }^{9}$ Inserm, U1235, University Nantes, CHU Nantes, Institut des Maladies de l'Appareil Digestif, Nantes, F-44000 France.

\section{Grant Support : none}

Abbreviations : computerized tomography , CT ; Crohn's disease, CD ; C-reactive Protein, CRP ; Groupe d'Etude Thérapeutique des Affections Inflammatoires Digestives, GETAID ; magnetic resonance imaging, MRI ; tumor necrosis factor, TNF ; abdominal ultrasound, US

\section{Correspondence:}

Guillaume Bouguen, MD, PhD

Service des Maladies de l'Appareil Digestif

2 rue Henri le Guillou 35033 Rennes cedex, FRANCE

Telephone (0033)-2-99-28-43-17 / Fax (0033)-2-99-28-41-89

Email: guillaume.bouguen@ chu-rennes.Fr

Conflicts of Interest: GB received lecture fees from Abbvie, Ferring, MSD, Takeda and Pfizer and consultant fees from Takeda, Janssen. LS received lecture fees from Abbvie, Ferring and MSD. LS received consultant fees from Takeda. AB received lecture fees from Abbvie, Ferring, Janssen, MSD, Medtronic, Takeda, Tillotts and consultant fees from Abbvie, Ferring, Janssen, MSD and Tillotts. JMR received lecture fees from Abbvie, Aptalis Pharma, Ferring, Hospira, Janssen, MSD, Pfizer, and Takeda, consultant fees from Ferring and Hospira, and participates in clinical research trials sponsored by Celgene, Gilead, Janssen, Lilly, Pfizer and Roche. MN received lecture fees from Abbvie, Ferring, MSD, Takeda and Pfizer and consultant fees from Biogen, Janssen and Boehringer-Ingelheim. Aurelien Amiot received consulting fees from Abbvie, Hospira, Takeda, Gilead and Biocodex as well as lecture fees and 
travel accommodations from Abbvie, Janssen, Biocodex, Hospira, Ferring, Takeda and MSD. This author also received advisory board fees from Gilead, Takeda and Abbvie. The other authors declare no competing interests.

Writing Assistance: Yes. Manuscript was reviewed by American Journal Expert@

Authors' contributions: conception and design of the study: AH, GB ; acquisition of data: all authors; analysis and interpretation of data GB drafting the article and all authors revised it critically for important intellectual. The manuscript was approved by all authors.

Acknowledgements: None. 
Abstract

Background \& Aims: Few data are available on the effects of tumor necrosis factor (TNF) antagonist therapy for patients with internal fistulizing Crohn's disease (CD) and there is debate over the risk of abscess. We aimed to assess the long-term efficacy and safety of antiTNF therapy for patients with internal fistulas.

Methods: We performed a retrospective study of data collected from Groupe d'Etude Thérapeutique des Affections Inflammatoires Digestives trial, from January 1, 2000 through December 31, 2017. Our final analysis included 156 patients who began treatment with an antiTNF agent for CD with internal fistula ( 83 men; median disease duration, 4.9 years). The primary endpoint was the onset of a major abdominal surgery. Secondary analysis included disappearance of the fistula tract during follow up and safety. The Kaplan-Meier method was used for statistical analysis.

Results: After a median follow-up of 3.5 years, 68 patients $(43.6 \%)$ underwent a major abdominal surgery. The cumulative probabilities for being surgery-free were $83 \%, 64 \%$, and $51 \%$ at 1,3 , and 5 years, respectively. A concentration of C-reactive protein $>18 \mathrm{mg} / \mathrm{L}$, albumin concentration $<36 \mathrm{~g} / \mathrm{L}$, presence of an abscess at the diagnosis of fistula, and presence of a stricture were independently associated with the need for surgery. The cumulative probabilities of fistula healing, based on imaging analyses, were $15.4 \%, 32.3 \%$, and $43.9 \%$ at 1 , 3 , and 5 years, respectively. Thirty-two patients (20.5\%) developed an intestinal abscess and 4 patients died from malignancies ( 3 intestinal adenocarcinomas). One patient died from septic shock 3 months after initiation of anti-TNF therapy.

Conclusions: In a retrospective analysis of data from a large clinical trial, we found that antiTNF therapy delays or prevents surgery for almost half of patients with CD and luminal fistulas. However, anti-TNF therapy might increase risk for sepsis-related death or gastrointestinal malignancies.

KEY WORDS: GETAID, inflammatory bowel disease, infliximab, prognostic factor 


\section{INTRODUCTION}

Crohn's disease (CD) is a chronic inflammatory disease of the gut that leads to bowel wall damage. One major dreaded complication during the CD course is the onset of a penetrating phenotype defined by the occurrence of luminal fistula tract(s) or B3 according to the Montreal

Classification ${ }^{1}$. The cumulative risk of penetrating disease (excluding perianal fistula) from population-based studies has been estimated to be as high as $41.7 \%$ at 30 years of age ${ }^{2}$.

This phenotype is the consequence of deep transmural ulcers perforating the whole intestinal wall, including the serosa, the mesentery and/or the adjacent organs. The Montreal B3 phenotype includes two types of luminal fistula: internal and external ${ }^{3}$. An external fistula corresponds to an abnormal tract between a bowel segment and the skin, also known as an entero-cutaneous fistula, that results in spontaneous drainage of the fistula tract at the skin surface. Note that perianal fistulae are not considered a B3 phenotype due to the substantial difference in pathogenesis and in medico-surgical treatment strategy ${ }^{4}$. Internal fistulae include all other luminal fistulae, such as entero-enteral or entero-organic fistulae. These types of internal luminal fistulas usually lead to a surgical procedure, particularly because of the risk of an abdominal abscess in the absence of spontaneous drainage ${ }^{5}$.

Tumor-necrosis factor antagonists (anti-TNF antibody treatment) have considerably changed the methods of treating inflammatory bowel diseases, particularly for perianal fistulizing diseases $^{6,7}$. To date, studies assessing the efficacy of anti-TNF treatment in fistulizing CD have primarily focused on entero-cutaneous fistulae, especially perianal fistulae ${ }^{5,8}$.

A GETAID (Groupe d'Etude Thérapeutique des Affections Inflammatoires Digestives) trial has recently assessed the efficacy of anti-TNF treatment for entero-cutaneous fistula in $51 \mathrm{CD}$ patients. A complete closure of fistula was obtained in $38 \%$ of patients who was sustained for half of the patients at 36 months $^{9}$. Few studies have reported the outcome of internal fistula treated with a TNF antagonist, which is probably due to the high rate of intestinal resection in this patient setting, which is related to the high risk of abscess for non-drained fistula ${ }^{9,10,11,12}$. The main report on this topic assessed retrospectively the need for surgery among 93 patients treated with anti-TNF agents for internal fistula: the cumulative rate of surgery and fistula 
closure rate at 5 years were $47.2 \%$ and $27 \%$, respectively. ${ }^{13}$ A similar rate of surgery was observed on a small series of 33 patients treated with TNF antagonist for entero-urinary Fistulas. $^{14}$

The aim of the present study was to assess the efficacy of anti-TNF treatment in a large cohort of CD patients with a luminal fistula. The secondary aims were to determine (1) which factors are associated with the need for surgery, (2) the rate of fistula healing following anti-TNF treatment, and (3) the rate and type of complications resulting from this medical strategy. 


\section{PATIENTS AND METHODS}

\section{Study design}

This report describes a multi-center retrospective study conducted over 17 years between January 1, 2000 and December 31, 2017. The study was conducted in GETAID centers and approved by ethics committee (Comité Consultatif sur le Traitement de l'Information en matière de Recherche dans le domaine de la Santé $\left.\mathrm{N}^{\circ} 16.326\right)$.

\section{Study population}

All consecutive CD patients who started an anti-TNF treatment for internal fistula during the study period were included. The diagnosis of internal fistula was based on conventional imaging, including computerized tomography (CT), magnetic resonance imaging (MRI) or abdominal ultrasound (US).

Patients with an ongoing anti-TNF treatment at the diagnosis of internal fistula were not included. In case of previous anti-TNF treatment exposure, patients were able to be included in the absence of any evidence of penetrating disease at anti-TNF withdrawal and when the discontinuation was performed at least 6 months before the diagnosis of fistula. Patients with entero-cutaneous peristomal, anastomotic and perianal fistulae were excluded.

Systematic screening of all patients with an established diagnosis of CD based on clinical, biological, radiological, endoscopic and/or histological evidence and who were treated by antiTNF treatment was performed in each referral center. The following data were recorded from the medical charts of the selected patients: age, gender, body weight, height, active smoking, familial history of $\mathrm{CD}$, date of $\mathrm{CD}$ diagnosis, Montreal classification at the time of $\mathrm{CD}$ diagnosis, personal history of abdominal surgery for CD (including surgeries for internal and perianal fistulae), and treatment history [i.e., previous exposure to anti-TNF treatment, immunosuppressive therapy (azathioprine, methotrexate)]. Internal fistula characteristics were assessed at fistula diagnosis and during the follow-up period (number of fistula tract(s), organs involved, presence of abscess, and concomitant stricture). All imaging was interpreted by an expert radiologist in the field of gastro-intestinal disease at each referral center. 
Clinical and biological features at the beginning of the anti-TNF treatment were collected. The reasons for surgery, type of intestinal resection, length of resection, and macroscopic and microscopic presence of fistula were retrieved from operation and pathological reports for each surgery case.

\section{Outcome measures and definition}

The primary endpoint was defined by the occurrence of an intestinal resection. The secondary outcomes were (1) the occurrence of internal fistula healing following anti-TNF treatment and (2) the safety profile of anti-TNF treatment.

An internal fistula was defined by a break of the intestinal wall associated with a visible tract outside the bowel. A complex internal fistula was defined by a fistula tract complicated with an abscess (more than one centimeter) and/or more than one fistula tract.

Major abdominal surgery was considered for those with intestinal resection at the location of the initial fistula tract(s). When surgery was performed for both fistula and stenosis without obstructive symptoms, only persistent fistula was considered. The main reason for surgery was collected (e.g., persistence of fistula, stricture, peritonitis, and cancer).

Fistula healing was defined by the disappearance of the fistula tract on imaging following antiTNF treatment initiation. The date of healing was the date of the first imaging without any observed fistula tract.

Adverse events were defined as any event occurring after anti-TNF treatment initiation that led to hospitalization and/or death.

\section{Statistical analysis}

Quantitative variables were presented as the median [interquartile range (IQR), 25\% and 75\%] and percentile. Categorical variables were presented as counts and the percentage of the cohort. A survival analysis was used to assess the probability of surgery and fistula healing. The cumulative probabilities of survival without an event were estimated by using the Kaplan- 
Meier method. The time to surgery and fistula healing was considered to begin at the date of anti-TNF treatment initiation and end at the date of the event.

To identify the predictive factors of each event, a univariate analysis was performed using the log-rank test. When considering the continuous variables for dichotomous analysis, cutoff values were determined using receiver operating characteristic (ROC) analysis to reduce the risk of bias related to arbitrarily defined cutoff values and to identify the optimal cutoff value by using onset of the surgery as a classification variable.

To identify the independent predictors of each event, a multivariate analysis was used. All significant variables with $p$-values $<0.05$ in the log-rank test were retained in the model and integrated into a Cox proportional hazards regression model. The results are shown as hazard ratios (HRs) with 95\% confidence intervals (Cis). Statistical analyses were performed using JMP Pro 13.2 software (SAS Institute Inc., Cary, NC). 


\section{RESULTS}

\section{Population characteristics}

A total of 156 patients were treated with anti-TNF for an internal fistula in 7 GETAID centers and constituted the study population. The characteristics of the 156 patients are provided in Table 1. Of note, 27 patients $(17.3 \%)$ were previously exposed to anti-TNF treatment, 67 (42.9\%) received immunosuppressive therapy and $66(42.3 \%)$ underwent a previous intestinal resection.

The internal fistula was complex in 96 patients $(61.5 \%)$ and complicated with an abscess in 65 cases $(41.6 \%)$. The diagnosis of the fistula was performed using CT in 72 patients (46.2\%), MRI in $69(44.2 \%)$ patients and US in 15 patients (9.6\%). There were $82(52 \%)$ patients with a simple fistula tract, $67(43 \%)$ patients with an enteroenteric fistula, $6(4 \%)$ patients with an enterovesical fistula and one woman had an enterouterine fistula. The localizations of the fistula are depicted in Table 1.

The median size of the abscesses was $25 \mathrm{~mm}$ [15-40], and percutaneous drainage of abscesses was performed in 11/65 (16.9\%) before starting anti-TNF treatment. A total of 13 patients presented with an abscess greater than $30 \mathrm{~mm}$ and did not undergo a percutaneous drainage related to the localization of the abscess inaccessible to the radiologist. The mean duration of percutaneous drainage was 15.5 days $[11.8-30.8]$. The median duration between the diagnosis of fistula and the introduction of anti-TNF treatment was 26 days (8-54). Concomitant treatments with the anti-TNF treatment are shown in Table 1. Of note, all patients with an abscess at diagnosis were treated using antibiotics with or without a percutaneous drainage before the use of anti-TNF. The duration of antibiotherapy was not available for all patients.

The anti-TNF treatment was infliximab in 117 patients (75\%) and adalimumab in 39 patients $(25 \%)$. All patient, with the exception of those who underwent early surgery, were treated with an induction regimen followed by regular maintenance regimen

\section{Need for surgery}

After a median follow-up of 3.5 years (1.8-5.5), 68 patients (43.6\%) underwent a major abdominal surgery.

The cumulative probabilities of being free of abdominal surgery after starting anti-TNF treatment were $83 \%, 64 \%$ and $51 \%$ at 1,3 and 5 years, respectively (Figure 1).

Indications for surgery included the absence of fistula healing in 43 patients (63.2\%) (median time from anti-TNF treatment initiation was 0.83 years [0.43-2.79]), and for 28 patients 
$(41.2 \%)$ there was an abscess at the date of surgery (median time from infliximab initiation was 3.45 years [0.87-4.02]). Of note, 9 patients had no prior history of abscess. Intestinal resection was performed in 20 patients $(29.4 \%)$ due to occlusion or sub-occlusion complicating concomitant stenosis after a median time from anti-TNF treatment initiation of 1.84 years [0.54-5.86]). Three patients (5.7\%) underwent intestinal resection for intestinal adenocarcinoma (please see below for details). Finally, 2 patients (3.8\%) had emergency surgery for intestinal perforation. The median length of intestinal resection was 30 [20 - 40] $\mathrm{cm}$.

The baseline factors significantly associated with the need for abdominal surgery following univariate analysis are reported in Table 2. These factors included abscess at the diagnosis of the luminal fistula, concomitant stricture of an inflamed bowel segment, low hemoglobin concentration, low albumin and a high CRP concentration at infliximab initiation. Within the subgroups of patients with an abscess at the diagnosis of the fistula, neither the size of the abscess nor the need for percutaneous drainage was associated with the need for surgery.

The optimal cut-off values for continuous variables obtained by ROC curve analysis were 12.5 $\mathrm{g} / \mathrm{dL}$ for hemoglobin, $18 \mathrm{mg} / \mathrm{L}$ for CRP and $36 \mathrm{~g} / \mathrm{L}$ for albumin.

From the multivariate analysis, CRP $>18 \mathrm{mg} / \mathrm{L}$ [HR $=2.12(1.25-3.71), \mathrm{p}=0.004]$, albumin < $36 \mathrm{~g} / \mathrm{L}[\mathrm{HR}=1.64(0.80-3.71), \mathrm{p}=0.01]$, presence of an abscess at the diagnosis of fistula $[\mathrm{HR}=1.68(1.03-2.73), \mathrm{p}=0.03]$ and presence of a bowel stricture $[\mathrm{HR}=1.88(1.13-3.21), \mathrm{p}=$ 0.01] were significantly and independently associated with the need for surgery (Table 2 and

\section{Figure 2).}

\section{Fistula healing}

A total of 148 patients $(94.8 \%)$ had at least one imaging evaluation since the introduction of anti-TNF treatment, and the other 8 patients were operated on before another imaging. Only MRI and CT were used to assess fistula healing. In the overall population, the fistula tract healed in 64 patients $(41 \%)$ following anti-TNF treatment, and 2 patients $(3.1 \%)$ relapsed over time. The median duration of the onset of fistula healing was 13.2 months $(6.1-26.48)$ following anti-TNF treatment. Within the subgroups of patients with an abscess at the diagnosis of the fistula, neither the size of the abscess nor the need for percutaneous drainage was associated with fistula healing.

Overall, the cumulative probabilities of sustained fistula healing were $15.4 \%, 32.3 \%$ and $43.9 \%$ at 1, 3 and 5 years after anti-TNF treatment initiation (Figure 3). 
Baseline factors significantly and independently associated with fistula healing in multivariate analysis were gender, concomitant bowel stricture, hemoglobin, and albumin concentrations (Table 3 and Figure 4).

\section{Adverse events}

A total of 44 serious adverse events following anti-TNF treatment were reported in the medical charts of the 156 included patients.

Infectious complications were the most frequent occurrence in 26 patients (14.0\%), 4 had extraintestinal sepsis (3.7\%), and 1 developed tuberculosis (0.9\%). Thirty-two patients (20.5\%) developed an intestinal abscess leading to surgery in 28 patients. This abscess was a recurrence for 21/32 (65\%) patients with an abscess at the diagnosis of the fistula and the first onset of an abscess for $11 / 32(35 \%)$ patients, $\mathrm{p}=0.002$. One 78 -year-old woman died from septic shock secondary to a sigmoid abscess 3 months after infliximab initiation. Of note, this woman was contraindicated for surgery at anti-TNF treatment initiation due to comorbidities.

Four patients (3.8\%) developed malignancies: intestinal adenocarcinoma for 3 patients (2.8\%) and melanoma for 1 patient $(0.9 \%)$. Regarding intestinal adenocarcinoma, 3 patients died, including a 33-year-old woman who died from a small bowel malignancy located at the fistula tract 6 years after the introduction of anti-TNF treatment and 20 years after CD diagnosis; a 33year-old man who died from a left colon cancer located at the fistula tract 7 years after the introduction of anti-TNF treatment and 20 years after CD diagnosis; and a 50-year-old man who died from a colon cancer located at the fistula tract 10 months after anti-TNF treatment initiation and 27 years after CD diagnosis. An endoscopic surveillance for dysplasia for the 2 last cases was performed 3 years earlier and at the initiation of anti-TNF treatment, respectively. No macroscopic or histologic feature for dysplasia were noted.

Overall, 4 patients $(3.7 \%)$ died after anti-TNF treatment initiation.

Other side effects of anti-TNF treatment were dermatological reaction (psoriasis-like), immune-allergic reaction (immediate hypersensitivity reaction) and pulmonary side effects (hypersensitivity pneumonitis). These effects occurred in 10 patients $(9.3 \%)$. 


\section{DISCUSSION}

Fistula is the second most common primary indication for surgery in $\mathrm{CD}^{1}$. The advent of biological therapy has profoundly changed treatment strategies in CD patients and has led to a decrease in, as well as a delayed need for, surgery. Nevertheless, there is little evidence considering the usefulness of these therapies in penetrating CD. The efficacy of anti-TNF treatment is well-known for perianal $^{5}$ and entero-cutaneous fistula ${ }^{8}$; therefore, its effect on internal fistula needs to be more accurately analyzed, especially in relation to the risk of sepsis. In our study, almost half of the patients receiving anti-TNF treatment for CD internal fistula required major abdominal surgery. Most of the surgeries were performed for persistent fistula or concomitant stenosis. The close relationship between fistula and stenosis is well-described with a usual postulate assuming that the occurrence of internal fistulae is favored by high prestenotic pressure ${ }^{15}$. The need for surgery for patients with a recurrence of abscess or the development of strictures underlined the inability of anti-TNF treatment to always control disease progression. The recent CREOLE study from the GETAID observed that anti-TNF treatment was effective for broadly $60 \%$ of patients and unable to avoid uncontrolled progression for the others. Of note fistulizing disease was associated with a decreased response rate that was also observed in the current study. ${ }^{16}$

The main strength of this work is the size and the multicenter design of the cohort with internal fistula. Surgery is usually the first choice of physicians in cases of internal fistula, and few patients are treated with anti-TNF therapy. Most studies on medical treatment for fistulizing CD addressed outcomes of all fistulae (perianal, external and internal) without subgroup analysis $^{10,12}$. A subgroup analysis of $4 \mathrm{CD}$ patients with internal fistulae in a small report of 36 fistulizing CD patients reported a failure of anti-TNF treatment (infliximab) to close internal fistulae in 3 patients who finally required surgery ${ }^{17}$. In another retrospective case-series, none of the internal fistulae of $4 \mathrm{CD}$ patients healed after 3 infliximab infusions ${ }^{11}$. In two larger cohorts, broadly half of patients were ultimately operated. ${ }^{13,14}$ Our data obtained from a large $\mathrm{CD}$ patient cohort clearly suggest that surgery is often required despite anti-TNF treatment. The need for surgery

Nevertheless, a significant number of internal fistulas healed after anti-TNF treatment. The cumulative probabilities of sustained fistula healing at 5 years were $47 \%$, which represented more than 1 of the 8 cases actually reported ${ }^{11,17}$. Fistula healing occurred on average 1 year following the introduction of anti-TNF treatment. 
Taken together, the use of anti-TNF treatment for fistulizing disease remains controversial with dichotomous outcomes (surgery or healing) in one out of two cases. Baseline factors associated with either surgery or fistula healing were similar and involved intestinal stricture, low albumin concentration and complex fistula. These results have to be confirmed in large prospective cohorts but suggest that a personalized strategy of treatment could be discussed according to radiological and biological characteristics. A complex fistula with low albumin concentrations and concomitant stenosis should be referred to a surgeon. Medical treatment could be attempted in other cases while being conscious of the risk of side effects.

One major limiting factor remains the adverse events in case of medical treatment. Side effects with biologic therapy for inflammatory bowel disease are common. In our population, severe adverse events occurred in $29.8 \%$, and death occurred for $3.7 \%$ of patients. Four patients developed non-intestinal sepsis. Clinical trials reported a similar rate of serious infections in 3 to $4 \%$ in infliximab-treated patients ${ }^{18}$. A specific risk of anti-TNF treatment is the development of an abdominal abscess. In our cohort, 11 patients developed an abscess after anti-TNF treatment initiation that led to surgery during the month following the occurrence of abscess in most cases or death in one case (a 78-year-old woman was initially recused from surgery).

A retrospective study of perianal fistula has reported abscess recurrence in $29 \%$ and abscess development during anti-TNF treatment in $16 \%$ of patients ${ }^{19}$. Regarding specific cases of internal fistulae, 3 of the $4 \mathrm{CD}$ patients reported by Miehsler et al. ${ }^{13}$ developed an abscess following anti-TNF treatment initiation, but these abscesses were already present at fistula diagnosis, and no drainage was done.

Occurrence of malignancy was significant in this study population. One case of malignant melanoma was reported 6 months after anti-TNF treatment initiation. Although a potential pathogenetic relationship remains controversial ${ }^{20,21}$, the risk of melanoma in patients treated with anti-TNF antibodies may be increased ${ }^{22}$. Three cases of solid malignancies were reported: 2 colon and 1 small bowel adenocarcinomas. All of the cancers developed at the initial fistula location. These patients had a long disease duration (more than 20 years) with an anti-TNF treatment that had a mean time of 6 years in 2 patients. Only one in three patients had concomitant exposure to immunosuppressive therapy (14 years). The close relationship between chronic inflammation and risk of cancer is well-recognized. Duration of disease is known to be the most important risk factor for colorectal cancer development and small bowel adenocarcinoma $^{23-25}$. In addition, several studies demonstrated a significant correlation between the severity of histological inflammation and the risk of colorectal neoplasia ${ }^{26,27}$. 
The third patient developed a colon adenocarcinoma 10 months after the diagnosis of internal fistula associated with colonic stricture. In CD strictures, it has recently been demonstrated that adenocarcinoma may be histologically indistinguishable from benign fibrotic or acute inflammatory stricture ${ }^{28}$. The two cases of colorectal cancer had no evidence of dysplasia with negative biopsies during the surveillanceSimilar assumptions could be made for CD internal fistulae. In the specific case of long-term CD patients with persistent severe and chronic intestinal inflammatory conditions, such as internal fistula, the benefits and risks of preferring medical therapy to surgery have to be weighted.

In addition to the retrospective design of the study, some limitations should be mentioned. First, no consensual definition of fistula healing is available. The disappearance of a fistula tract in imaging was considered to define healing. Furthermore, time to healing should be interpreted with caution because the dates of first and subsequent imaging were not standardized. There is still a lack of established definitions. The different antibiotic use regimens (type and duration) precluded the assessment of their possible positive effects on fistula healing, as suggested in the ADAFI trial on perianal fistulizing disease. ${ }^{29}$

In conclusion, the present results suggest that anti-TNF treatment could be an alternative to surgery but has to be discussed case by case according to the imaging and clinico-biological characteristics of penetrating CD. Anti-TNF treatment may be proposed for well-nourished patients without long disease duration and concomitant stenosis. Regarding the risk of complications and cancer, other patients should be referred to the surgeon, as well as patients with persistent fistula in imaging for over one to two years. Dedicated studies balancing the benefit/risk ratio in this specific population should be performed. A larger multicentric cohort from the GETAID centers will be formed to validate these results. 


\section{Tables and Figures}

Table 1 - Study population: baseline characteristics (abbreviation: CD, Crohn's disease ; CRP, C-reactive Protein)

Table 2 - Factors associated with surgery according to univariate and multivariate analyses (abbreviation: CD, Crohn's disease ; CRP, C-reactive Protein)

Table 3 - Factors associated with fistula-healing following anti-TNF treatment by univariate and multivariate analyses. (abbreviation: CD, Crohn's disease ; CRP, C-reactive Protein)

Figure 1 - Kaplan-Meier curve of cumulative probabilities of being surgery-free following anti-TNF treatment for internal fistula (A) and for factors associated with the need for surgery according to multivariable analysis, including the presence of an abscess at fistula diagnosis (B), the presence of concomitant luminal stenosis (C) and the CRP range at anti-TNF initiation (D).

Figure 2 - Kaplan-Meier curve of cumulative probabilities of internal fistula healing following anti-TNF treatment (A) and factors associated with internal fistula healing according to multivariable analysis, including the presence of concomitant luminal stenosis (B) albumin (Alb) (C) and Hemoglobin (Hb) (D) concentrations at anti-TNF initiation. 


\section{REFERENCES}

1. Silverberg MS, Satsangi J, Ahmad T, et al. Toward an integrated clinical, molecular and serological classification of inflammatory bowel disease: report of a Working Party of the 2005 Montreal World Congress of Gastroenterology. Can J Gastroenterol 2005;19 Suppl A:5A-36A.

2. Thia KT, Sandborn WJ, Harmsen WS, et al. Risk factors associated with progression to intestinal complications of Crohn's disease in a population-based cohort. Gastroenterology 2010;139:1147-55.

3. Satsangi J, Silverberg MS, Vermeire S, et al. The Montreal classification of inflammatory bowel disease: controversies, consensus, and implications. Gut 2006;55:749-53.

4. Louis E, Collard A, Oger AF, et al. Behaviour of Crohn's disease according to the Vienna classification: changing pattern over the course of the disease. Gut 2001;49:77782.

5. Pola S, Patel D, Ramamoorthy S, et al. Strategies for the care of adults hospitalized for active ulcerative colitis. Clin Gastroenterol Hepatol 2012;10:1315-1325 e4.

6. Hanauer SB, Feagan BG, Lichtenstein GR, et al. Maintenance infliximab for Crohn's disease: the ACCENT I randomised trial. Lancet 2002;359:1541-9.

7. Present DH, Rutgeerts P, Targan S, et al. Infliximab for the treatment of fistulas in patients with Crohn's disease. N Engl J Med 1999;340:1398-405.

8. Ricart E, Panaccione R, Loftus EV, et al. Infliximab for Crohn's disease in clinical practice at the Mayo Clinic: the first 100 patients. Am J Gastroenterol 2001;96:722-9.

9. Amiot A, Setakhr V, Seksik P, et al. Long-term outcome of enterocutaneous fistula in patients with Crohn's disease treated with anti-TNF therapy: a cohort study from the GETAID. Am J Gastroenterol 2014;109:1443-9.

10. Gardiner KR, Dasari BV. Operative management of small bowel Crohn's disease. Surg Clin North Am 2007;87:587-610.

11. Miehsler W, Reinisch W, Kazemi-Shirazi L, et al. Infliximab: lack of efficacy on perforating complications in Crohn's disease. Inflamm Bowel Dis 2004;10:36-40.

12. Ochsenkuhn T, Goke B, Sackmann M. Combining infliximab with 6mercaptopurine/azathioprine for fistula therapy in Crohn's disease. Am J Gastroenterol 2002;97:2022-5.

13. Kobayashi T, Hishida A, Tanaka H, et al. Real-world Experience of Anti-tumor Necrosis Factor Therapy for Internal Fistulas in Crohn's Disease: A Retrospective Multicenter Cohort Study. Inflamm Bowel Dis 2017;23:2245-2251.

14. Taxonera C, Barreiro-de-Acosta M, Bastida G, et al. Outcomes of Medical and Surgical Therapy for Entero-urinary Fistulas in Crohn's Disease. J Crohns Colitis 2016;10:65762.

15. Oberhuber G, Stangl PC, Vogelsang H, et al. Significant association of strictures and internal fistula formation in Crohn's disease. Virchows Arch 2000;437:293-7.

16. Bouhnik Y, Carbonnel F, Laharie D, et al. Efficacy of adalimumab in patients with Crohn's disease and symptomatic small bowel stricture: a multicentre, prospective, observational cohort (CREOLE) study. Gut 2018;67:53-60.

17. Poritz LS, Rowe WA, Koltun WA. Remicade does not abolish the need for surgery in fistulizing Crohn's disease. Dis Colon Rectum 2002;45:771-5.

18. Sands BE, Anderson FH, Bernstein CN, et al. Infliximab maintenance therapy for fistulizing Crohn's disease. N Engl J Med 2004;350:876-85. 
19. Bouguen G, Siproudhis L, Gizard E, et al. Long-term outcome of perianal fistulizing Crohn's disease treated with infliximab. Clin Gastroenterol Hepatol 2013;11:975-81 e14.

20. Magro F, Peyrin-Biroulet L, Sokol H, et al. Extra-intestinal malignancies in inflammatory bowel disease: results of the 3rd ECCO Pathogenesis Scientific Workshop (III). J Crohns Colitis 2014;8:31-44.

21. Williams CJ, Peyrin-Biroulet L, Ford AC. Systematic review with meta-analysis: malignancies with anti-tumour necrosis factor-alpha therapy in inflammatory bowel disease. Aliment Pharmacol Ther 2014;39:447-58.

22. Long MD, Martin CF, Pipkin CA, et al. Risk of melanoma and nonmelanoma skin cancer among patients with inflammatory bowel disease. Gastroenterology 2012;143:390-399 e1.

23. Cahill C, Gordon PH, Petrucci A, et al. Small bowel adenocarcinoma and Crohn's disease: any further ahead than 50 years ago? World J Gastroenterol 2014;20:11486-95.

24. Choi PM, Zelig MP. Similarity of colorectal cancer in Crohn's disease and ulcerative colitis: implications for carcinogenesis and prevention. Gut 1994;35:950-4.

25. Gillen CD, Walmsley RS, Prior P, et al. Ulcerative colitis and Crohn's disease: a comparison of the colorectal cancer risk in extensive colitis. Gut 1994;35:1590-2.

26. Askling J, Dickman PW, Karlen P, et al. Colorectal cancer rates among first-degree relatives of patients with inflammatory bowel disease: a population-based cohort study. Lancet 2001;357:262-6.

27. Zisman TL, Rubin DT. Colorectal cancer and dysplasia in inflammatory bowel disease. World J Gastroenterol 2008;14:2662-9.

28. Fumery M, Pineton de Chambrun G, Stefanescu C, et al. Detection of Dysplasia or Cancer in $3.5 \%$ of Patients With Inflammatory Bowel Disease and Colonic Strictures. Clin Gastroenterol Hepatol 2015;13:1770-5.

29. Dewint P, Hansen BE, Verhey E, et al. Adalimumab combined with ciprofloxacin is superior to adalimumab monotherapy in perianal fistula closure in Crohn's disease: a randomised, double-blind, placebo controlled trial (ADAFI). Gut 2014;63:292-9. 
Table 4 - Study population: Baseline characteristics

\begin{tabular}{|c|c|}
\hline VARIABLES & $\begin{array}{c}\text { Overall population } \\
n=156\end{array}$ \\
\hline \multicolumn{2}{|l|}{ CHARACTERISTICS OF CD } \\
\hline Male sex $-\mathrm{n}(\%)$ & $83(53)$ \\
\hline \multicolumn{2}{|l|}{ CD phenotype (Montreal Classification) $-\mathrm{n}(\%)$} \\
\hline $\mathrm{L} 1 / \mathrm{L} 2 / \mathrm{L} 3$ & $68(44) / 10(6) / 78(50)$ \\
\hline History of perianal disease $-\mathrm{n}(\%)$ & $55(35)$ \\
\hline Family history of IBDs - n (\%) & $17(11)$ \\
\hline Personal surgical history $-\mathrm{n}(\%)$ & $66(42)$ \\
\hline \multicolumn{2}{|l|}{ CHARACTERISTICS AT FISTULA DIAGNOSIS } \\
\hline Age (years) - median [IQR 25\% - 75\%] & $32(24-39.6)$ \\
\hline Smoking status: active / ex-smoker / no smoker - n (\%) & $59(38) / 18(12) / 77(50)$ \\
\hline Duration of CD (years) - median (IQR 25\% - 75\%) & $4.9(0.5-12.1)$ \\
\hline Complex fistula $-\mathrm{n}(\%)$ & $96(61)$ \\
\hline Abcess $-\mathrm{n}(\%)$ & $65(41)$ \\
\hline$>1$ fistula tract $-\mathrm{n}(\%)$ & $46(29)$ \\
\hline \multicolumn{2}{|l|}{ Type and localization of the fistula } \\
\hline Simple fistula tract & $82(52)$ \\
\hline Ileal & $74(47)$ \\
\hline Colic & $8(5)$ \\
\hline Enteroenteric & $67(43)$ \\
\hline Ileo-ileal & $31(20)$ \\
\hline Ileo-colic & $34(22)$ \\
\hline Colo-Colic & $1(1)$ \\
\hline Colo-duodenal & $1(1)$ \\
\hline Enterouterine & $1(1)$ \\
\hline Enterovesical & $6(4)$ \\
\hline Ileo-colo-vesical & $3(2)$ \\
\hline Ileo-vesical & $3(2)$ \\
\hline Concomitant stenosis $-\mathrm{n}(\%)$ & $92(59)$ \\
\hline \multicolumn{2}{|c|}{ CHARACTERISTICS AT ANTI-TNF TREATMENT INTRODUCTION } \\
\hline \multicolumn{2}{|l|}{ Biological characteristics - median (IQR 25\% - 75\%) } \\
\hline Haemoglobin $(\mathrm{g} / \mathrm{dL})$ & $12.3(11.3-13.6)$ \\
\hline Leukocytes (G/L) & $8.0(6.0-10.7)$ \\
\hline Albumin $(\mathrm{g} / \mathrm{L})$ & $34.9(33-36.8)$ \\
\hline CRP (mg/L) & $16.6(5.0-39.8)$ \\
\hline \multicolumn{2}{|l|}{ Concomitant treatment $-\mathrm{n}(\%)$} \\
\hline Antibiotics & $84(54)$ \\
\hline Steroids & $59(38)$ \\
\hline Immunosuppressant & $44(28)$ \\
\hline
\end{tabular}


Table 5 - Factors associated with surgery by univariate and multivariate analyses

\begin{tabular}{|c|c|c|}
\hline Covariates & $\begin{array}{c}\text { Univariate } \\
\text { analysis }\end{array}$ & $\begin{array}{c}\text { Multivariate } \\
\text { analysis }\end{array}$ \\
\hline & p value & HR $(95 \% \mathrm{CI}), p$ value \\
\hline Male sex & 0.21 & \\
\hline \multicolumn{3}{|l|}{ CD phenotype (Montreal Classification) } \\
\hline $\mathrm{L} 1 / \mathrm{L} 2 / \mathrm{L} 3$ & $0.98 / 0.95 / 0.99$ & \\
\hline Family history of IBD & 0.56 & \\
\hline Personal surgical history & 0.97 & \\
\hline Age at fistula diagnosis & 0.43 & \\
\hline Active smoking status & 0.66 & \\
\hline History of perianal disease & 0.42 & \\
\hline Duration of CD at fistula diagnosis & 0.88 & \\
\hline \multicolumn{3}{|l|}{ Fistula characteristics } \\
\hline Abscess & 0.02 & $1.68(1.03-2.73), 0.03$ \\
\hline$>1$ fistula tract & 0.47 & \\
\hline Type of Fistula & 0.89 & \\
\hline Concomitant stenosis $-\mathrm{n}(\%)$ & 0.03 & $1.88(1.13-3.21), 0.01$ \\
\hline \multicolumn{3}{|c|}{ Biological characteristics at anti-TNF initiation } \\
\hline Hemoglobin $<12.5 \mathrm{~g} / \mathrm{dL}$ & 0.007 & $1.59(0.94-2.74), 0.07$ \\
\hline Albumin $<36 \mathrm{~g} / \mathrm{L}$ & 0.004 & $1.64(0.80-3.71), 0.18$ \\
\hline $\mathrm{CRP}>18 \mathrm{mg} / \mathrm{L}$ & 0.002 & $2.12(1.25-3.71), 0.004$ \\
\hline \multicolumn{3}{|c|}{ Concomitant treatment at anti-TNF initiation } \\
\hline Steroids & 0.92 & \\
\hline Immunosuppressant & 0.51 & \\
\hline
\end{tabular}




\section{ACCEPTED MANUSCRIPT}

Table 6 - Factors associated with fistula healing following anti-TNF treatment by univariate and multivariate analyses

\begin{tabular}{|c|c|c|}
\hline Covariates & $\begin{array}{c}\text { Univariate } \\
\text { analysis }\end{array}$ & $\begin{array}{c}\text { Multivariate } \\
\text { analysis }\end{array}$ \\
\hline & p value & HR $(95 \% \mathrm{CI}), p$ value \\
\hline Female sex & 0.02 & $0.46(0.26-0.79), 0.005$ \\
\hline \multicolumn{3}{|l|}{ CD phenotype (Montreal Classification) } \\
\hline $\mathrm{L} 1 / \mathrm{L} 2 / \mathrm{L} 3$ & $0.32 / 0.63 / 0.23$ & \\
\hline Personal surgical history & 0.99 & \\
\hline Age at fistula diagnosis & 0.52 & \\
\hline Active smoking status & 0.58 & \\
\hline Duration of $\mathrm{CD}$ at fistula diagnosis & 0.18 & \\
\hline \multicolumn{3}{|l|}{ Fistula Characteristics } \\
\hline Abscess & 0.17 & \\
\hline$>1$ fistula tract & 0.18 & \\
\hline Type of Fistula & 0.70 & \\
\hline Concomitant stenosis $-\mathrm{n}(\%)$ & 0.06 & $0.52(0.30-0.89), 0.02$ \\
\hline \multicolumn{3}{|c|}{ Biological characteristics at anti-TNF initiation } \\
\hline Haemoglobin $<12.5 \mathrm{~g} / \mathrm{dL}$ & 0.008 & $0.54(0.29-0.98), 0.04$ \\
\hline Albumin $<36 \mathrm{~g} / \mathrm{L}$ & 0.0002 & $0.52(0.29-0.93), 0.03$ \\
\hline $\mathrm{CRP}>18 \mathrm{mg} / \mathrm{L}$ & 0.009 & $0.68(0.38-1.20), 0.19$ \\
\hline \multicolumn{3}{|c|}{ Concomitant treatment at anti-TNF treatment initiation } \\
\hline & 0.58 & \\
\hline Immunosuppressant & 0.82 & \\
\hline
\end{tabular}



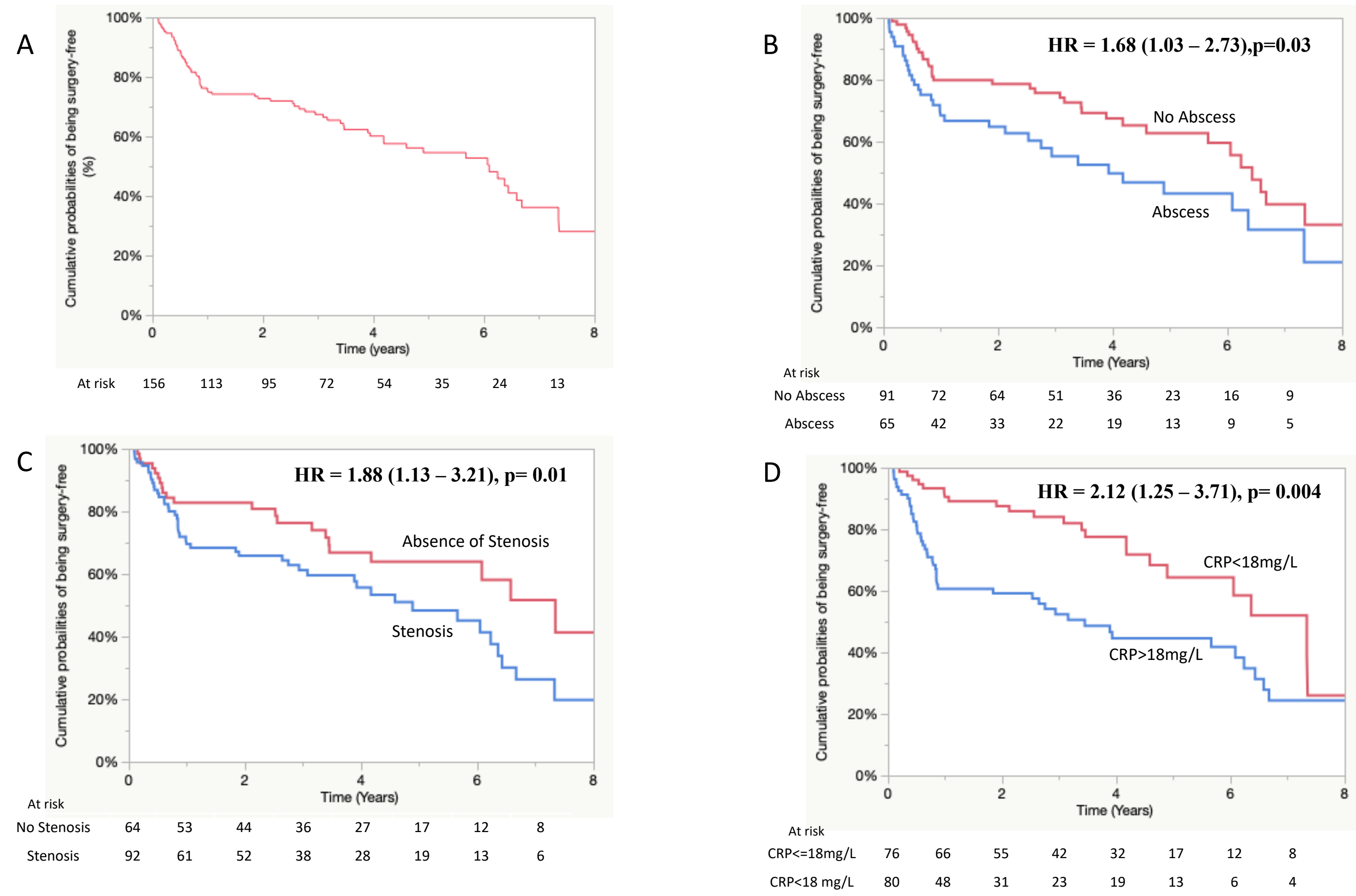

Fig. 1 
A

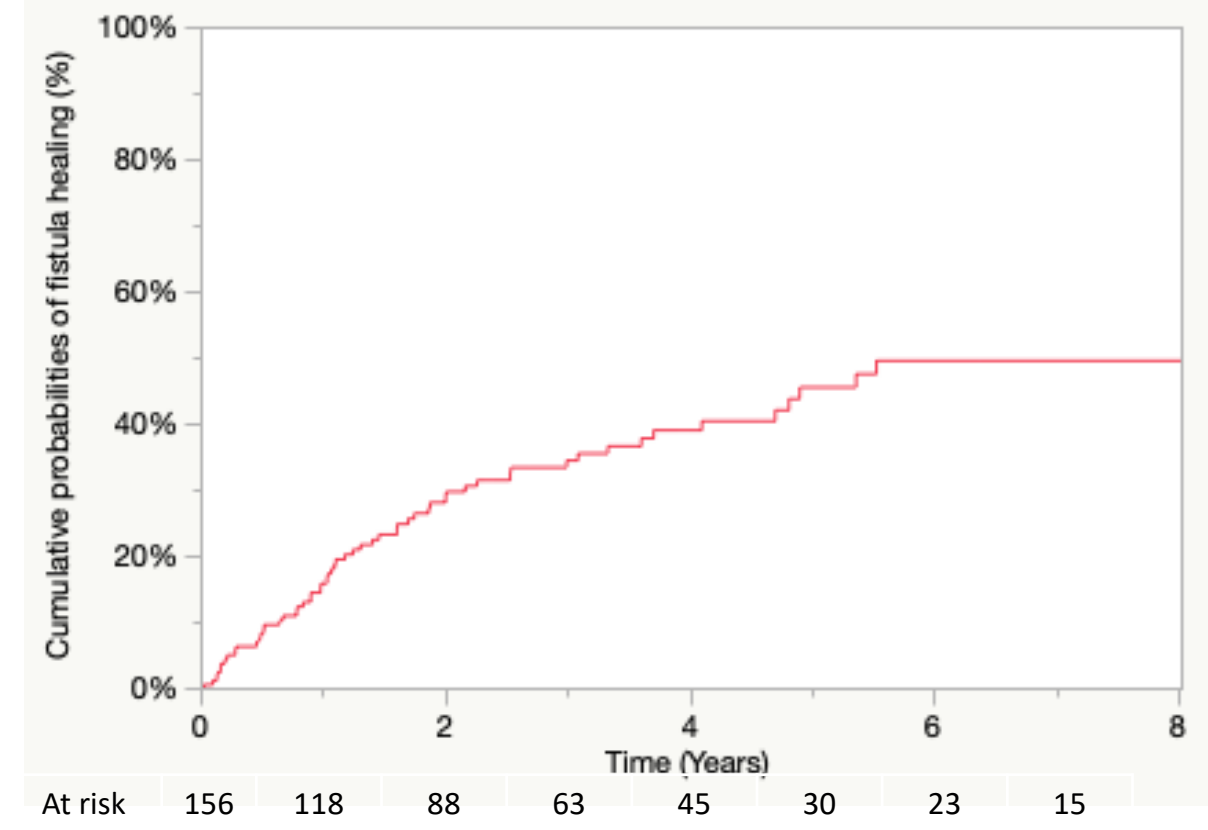

At risk

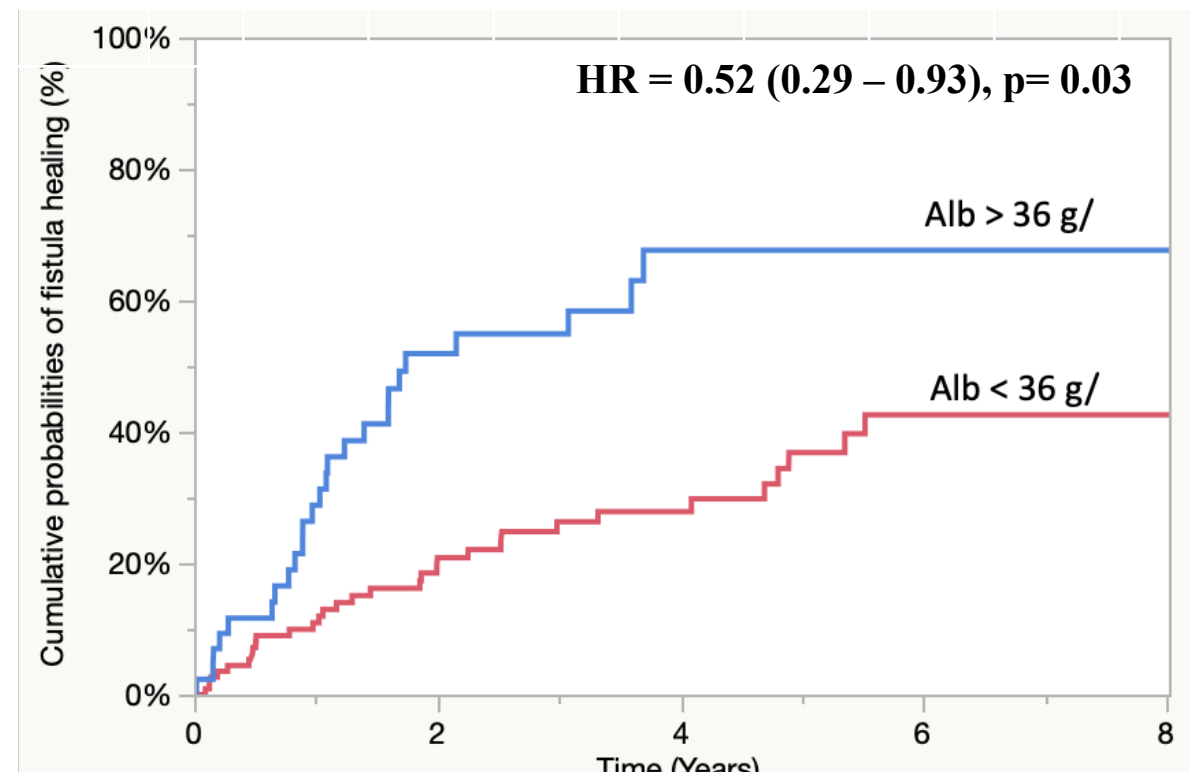

C

At risk

\begin{tabular}{|l|l|l|l|l|l|l|l|l|}
\hline Alb $<36 \mathrm{~g} / \mathrm{L}$ & 113 & 89 & 70 & 50 & 38 & 25 & 18 & 12 \\
\hline
\end{tabular}

\begin{tabular}{|l|l|l|l|l|l|l|l|l|l|}
\hline Fig. 2 & Alb $<36 \mathrm{~g} / \mathrm{L}$ & 43 & 30 & 19 & 14 & 8 & 6 & 6 & 4 \\
\hline
\end{tabular}

B

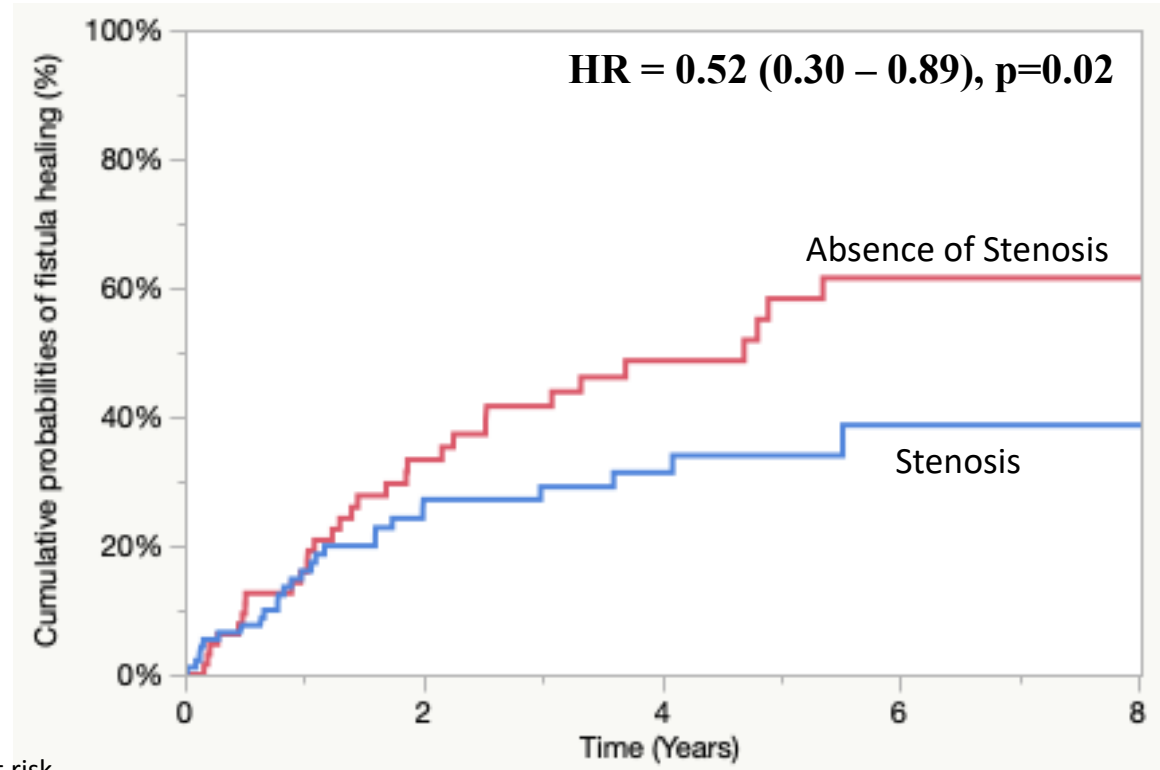

At risk

$\begin{array}{lllllllll}\text { Stenosis } & 76 & 66 & 55 & 42 & 32 & 17 & 12 & 8\end{array}$

$\begin{array}{lllllllll}\text { No Stenosis } & 64 & 52 & 37 & 27 & 19 & 14 & 11 & 9\end{array}$

D

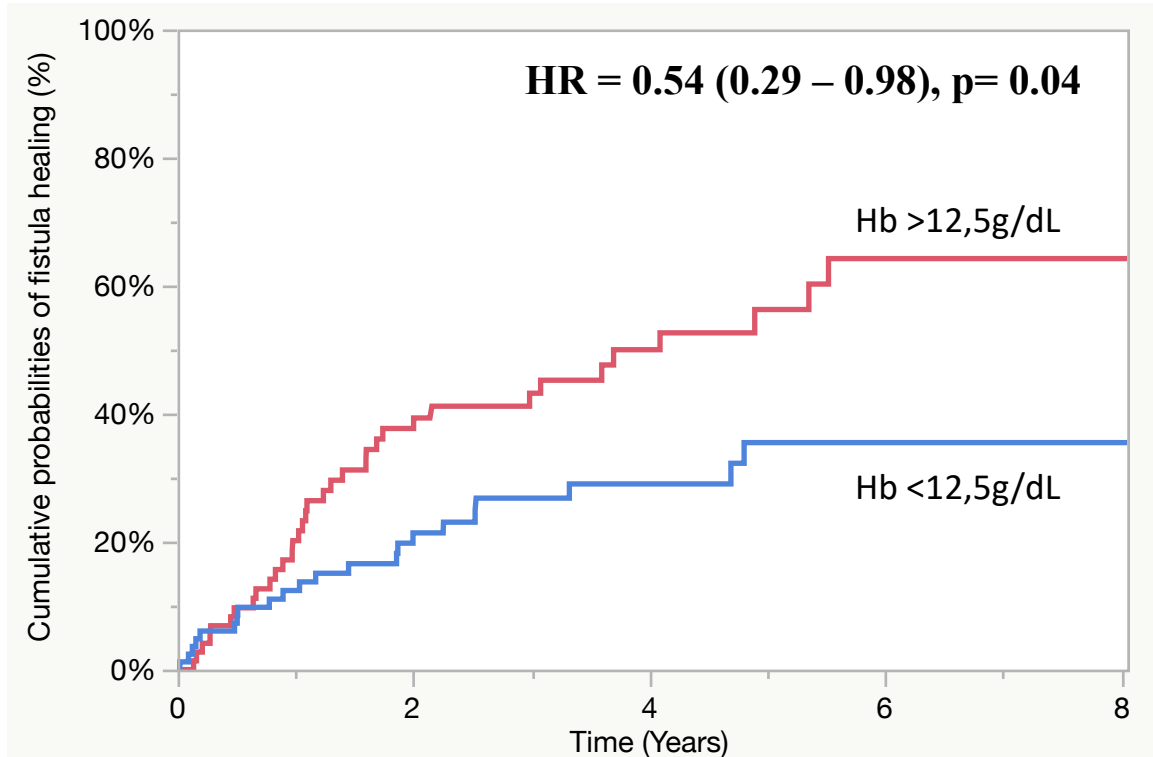

At risk

$\mathrm{Hb}>12,5 \mathrm{~g} / \mathrm{dL}$

$\mathrm{Hb}<12,5 \mathrm{~g} / \mathrm{dL}$

$\begin{array}{llllllll}73 & 52 & 40 & 29 & 20 & 12 & 6 & 2 \\ 83 & 66 & 50 & 35 & 26 & 19 & 15 & 5\end{array}$




\section{What You Need to Know}

Background: We investigated the effects of tumor necrosis factor (TNF) antagonist therapy for patients with internal fistulizing Crohn's disease (CD), assessing long-term efficacy and safety using data from a clinical trial.

Findings: Anti-TNF therapy delayed or prevented surgery for almost half of patients with CD and luminal fistulas. However, non-operated patients may have an increased risk of cancer.

Implications for patient care: Anti-TNF therapy helps patients with luminal fistulas delay or avoid surgery, but they should be monitored for infections and gastrointestinal malignancies. 